\title{
A STUDY ON IMPROVING DYEABILITY OF POLYESTER FABRIC USING LIPASE ENZYME
}

\author{
Jeyaraman Anandha Kumar ${ }^{1 *}$, M. Senthil Kumar² \\ 1 Department of Textile Processing, GRG Polytechnic College, Kuppepalayam, Sarkar Samakulam, Coimbatore, India \\ 2 Department of Textile Technology, PSG College of Technology, Peelamedu, Coimbatore, India \\ E-mail: anna_781@rediffmail.com
}

\begin{abstract}
:
Enzymatic hydrolysis on synthetic fibers enhances the hydrophilicity and solves the concerns regarding the environmental issues of textile industry. Lipase hydrolyses ester linkages in polyethylene terephthalate and produces polar hydroxyl and carboxylic groups. The study aims to identify and investigate the effect of enzyme treatment on weight loss and surface modification of polyester fabrics. Also the functional groups present before and after treatment and the effect of enzyme treatment on the improvement of dye uptake are studied. The test indicates that enzymatic process creates less surface damage, weight loss and improved moisture regain, dye uptake, and shear properties.
\end{abstract}

\section{Keywords:}

Enzymatic hydrolysis, polyethylene terephthalate, weight loss, shear properties

\section{Introduction}

Polyethylene terephthalate (PET) is one of the most commonly used synthetic fiber [1]. Merits of PET include high strength, high stretch resistance, washability, wrinkle resistance, and abrasion resistance [2, 3]. However, PET has undesirable properties such as pilling, static, and lack of dyeability associated with its hydrophobic nature. PET fiber has a low moisture regain of about $0.4 \%$ [4]. The most conventional and industrial way to modify polyester fabrics is alkaline treatment [5-7], but alkaline treatment affects the strength of polyester fabrics. A recent alternative is the use of enzymes in surface modification [810]. Studies about enzymatic treatment of polyester have been focused on biodegradation of aliphatic polyester using a lipase and biological synthesis of polymer with enzymes [11, 12]. Only a few studies have been reported regarding enzymatic modification of PET fabric [13]. Improvement in hydrophilicity of polyesters by hydrolysis of ester bonds has been reported [14] The applicable enzymes used are lipases and polyesterases. Lipase is known to hydrolyze water-insoluble esters or triglycerides composed of long-chain fatty acids [15]. Thus, the application and studies about lipases in textile processing have been focused on detergent. If enzymes can hydrolyze ester linkage in PET fabrics, polar hydroxyl $(-\mathrm{OH})$ and carboxyl ($\mathrm{COOH}$ ) groups will be formed on the surface of PET fabrics. As a result, moisture regains and wettability will improve due to the forming of hydrophilic groups on PET fabrics. Carboxyl and hydroxyl groups on PET fabrics can be evaluated through dyeability of disperse dyes. Hydrolysis of the ester bond creates carboxylic and hydroxyl groups within the polyester fabrics [16]. Under optimum conditions, lipase enzymes of different sources significantly improve the hydrophilicity and dyeability of PETtreated fabrics [17]. Enzymes active on PET substrates include various cutinases, lipases, and esterases. The enzymatic modification of $\mathrm{PET}^{5}$ implies the limited hydrolysis of backbone ester bonds, which generates new free hydroxyl and carboxyl groups at the polymer surface, thus leading to increased hydrophilicity of the PET substrate, as shown in Figure 1.

\subsection{Aminolysis}

Several studies have assessed the effects of amine interaction with polyester. Early studies assessed the aminolysis of polyester as a means of examining fiber structure without maintaining the integrity of the polymer. The degradation<smiles>[R]OCCOC(=O)c1ccc(C(=O)OCCOP)cc1</smiles>

Figure 1. Enzymatic hydrolysis of polyethylene terephthalate (PET) 
effects on polyester of a monofunctional amine versus alkaline hydrolysis have been studied. These studies, which again involved high levels of fiber degradation, demonstrated that alkaline hydrolysis has a more substantial effect on fiber weight without extensive strength loss. In contrast, aminolysis had less effect on fiber weight but decreased fiber strength, indicative of a reaction within the polymer structure rather than simply at the surface. It was later demonstrated that bifunctional amine compounds could be reacted with the polymer with minimal loss in strength while generating amine groups at the fiber surface. The early stages of the reaction were largely confined to the fiber surface and the resulting fiber had modified wetting properties and improved adhesion with the matrix when used in composites [18].

\section{Materials and methods}

In this study, $100 \%$ polyester fabric plain weave was used to know the effect of enzyme treatment on the structural modifications. Polyethylene terephthalate, PET, heat set fabric having a surface mass of $82 \mathrm{~g} / \mathrm{m}^{2}$ was used for this study; textured multifilament yarns in both warp and weft directions. Yarn consisted of delustered fibers with trilobal cross-section in warp and circular cross-section in weft. Fabric and enzyme specifications are discussed in Tables 1 and 2 and labels are given in Table 3 . The fabrics are subjected to washing to eliminate the presence of impurities and finishes. Fabrics are treated with enzymes of varying concentrations, treatment time, and temperatures. The fabrics selected for the experiments are subjected to alkali and lipase treatment with different concentrations, namely $5 \%, 10 \%$, and $15 \%$. The fabrics are dyed with disperse dye C.I. Disperse Blue 284 with a shade level of $5 \%$ on weight of the fabric. The treated fabrics are dyed using disperse dye with high-temperature high-pressure dyeing machine. The fabric weave is a plain weave and the chemicals used in this work were laboratory grade reagents.

\subsection{Pretreatment of polyester fabric}

Polyester fabric was immersed in $10 \mathrm{gpl} \mathrm{HCl}$ at $40^{\circ} \mathrm{C}$ and treated for 1 hour at the same temperature with material to liquor ratio of 1:50, to get rid of the added impurities [19].

\subsection{Sodium hydroxide treatment}

The pretreated PET fabrics were subjected to various concentrations of sodium hydroxide treatment at boil for 1 hour and 2 hours of treatment time.

\subsection{Lipase enzyme treatment}

Each fabric sample was cut into specific dimensions and weighed $\sim 1 \mathrm{~g}$. Depending on $\mathrm{pH}$, temperature, concentration, and treatment time, the PET fabrics were treated with lipase in Tris buffer solution, using a liquor ratio of $80: 1$. All the lipase treatments were performed at $150 \mathrm{rpm}$ using a shaking water bath. The enzyme inactivation was performed at $80^{\circ} \mathrm{C}$ for 10 minutes. The lipase-treated samples were thoroughly washed with water and dried at room temperature. Then, weight loss, scanning electron microscope (SEM) micrographs, water vapor permeability, Fourier transform infrared spectroscopy (FTIR), Color analysis, and low-stress mechanical properties of lipase-treated PET fabrics were measured.

\subsection{Dyeing}

Enzyme-treated as well as sodium hydroxide-treated polyester fabrics were dyed using $0.5 \%$ (owf) dianix navy S2G (disperse dye), C.I. Disperse Blue 284 and $1 \mathrm{~g} / \mathrm{L}$ dispersing agent in a HTHP dyeing machine. The dyeing was carried out at a temperature of $130^{\circ} \mathrm{C}$ and at $\mathrm{pH} 5$ (adjusted by acetic acid). The dyed samples were washed with hot water, soaped, and dried.

\section{Analytical methods}

\subsection{Weight loss evaluation}

The weight loss (WL) is expressed as relative $\mathrm{WL}$ according to the equation:

$W L=100 *(W 1-W 2) / W 1)$

where $\mathrm{W} 1$ and $\mathrm{W} 2$ are the weights of the samples before and after treatment, respectively.

\subsection{Wicking height measurement}

The wicking heights of the treated fabrics are tested as per AATCC Test Method 197 to evaluate the specimens to transport liquid along them. The distance at a given time is measured.

\subsection{Absorbency measurement}

The water absorbency of treated fabrics is tested as per AATCC Test Method 79 to know the time taken by a drop of water placed on the fabric surface to completely absorb.

\subsection{SEM analysis}

The enzyme-treated polyester and blended samples are analyzed through SEM to know the effect of enzyme treatment on surface etching. The surface morphology of polyester fabrics was observed in SEM (JOEL JSM-6360).

\subsection{FTIR analysis}

FTIR tests were carried out to reveal the additional functional groups present due to alkaline and enzymatic hydrolysis. The attenuated total reflectance-Fourier transform infrared spectroscopy (ATR-FTIR) measurements were carried out on polyester fabrics (control and treated) using an infrared spectroscopy. Nicolet IR200 FT-IR system with a singlereflection attenuated total reflectance attachment was used. Solid samples are prepared by shaving material off of the part that is thin enough to obtain a good FTIR spectrum. The x-axis 
Table 1. Fabrics specifications

\begin{tabular}{|c|c|c|c|c|c|c|}
\hline Fabric type & Weave & Linear density & Ends/inch & Picks/inch & Thickness (mm) & GSM \\
\hline Polyester (100\%) & Plain & $75^{\star} 77$ Denier & 120 & 94 & 0.18 & 82 \\
\hline
\end{tabular}

Table 2. Enzyme specifications

\begin{tabular}{|c|c|c|c|}
\hline $\begin{array}{c}\text { Name of the } \\
\text { enzyme }\end{array}$ & Activity & Form & Manufacturer \\
\hline Lipolase 100L-EX & $100,000 \mathrm{U} / \mathrm{g}$ & Liquid & Novozyme \\
\hline
\end{tabular}

is wavenumber $(\mathrm{cm}-1)$, which is the inverse of wavelength (cm). The y-axis is absorbance normalized on a scale of 0 to 1 , where 0 denotes no absorption and 1 denotes maximum absorption.

\subsection{Water vapor permeability measurement}

The water vapor transmission rates of treated fabrics are tested as per ASTM D6701-16 using water vapor permeability tester.

\subsection{Color measurements}

The relative color strength $(K / S)$ of dyed fabrics was measured using SS5100A spectrophotometer premier color scan by the light reflectance technique at a wave length 400-700 nm. Reflectance values were measured and the relative color strength $(K / S)$ was calculated using Kubelka-Munk equation. $K / S$ defines a relationship between spectral reflectance I of sample and its absorption $(K)$ and scattering $(S)$ characteristics.

\subsection{Evaluation of low-stress mechanical properties}

The Kawabata Evaluation System of Fabric (KESF) tester is used to measure the low-stress mechanical properties of alkaline- and lipase-treated fabrics.

\subsection{Statistical analysis}

To understand the significance of various test results, statistical parameters are analyzed using SYSTAT Software. The statistical parameters like $t$-test, correlation coefficient, and regression equation were derived.

Table 4. Effect of lipase treatment on weight loss of polyester fabrics
Table 3. Labels and treatments

\begin{tabular}{|c|c|c|}
\hline S. No. & Treatment & Label \\
\hline 1 & Untreated polyester fabric (100\%) & PU \\
\hline 2 & Alkaline-treated polyester fabric & PA \\
\hline 3 & Lipase-treated polyester fabric & PL \\
\hline 4 & Dyed alkaline treated & PAD \\
\hline 5 & Dyed lipase-treated fabric & PLD \\
\hline
\end{tabular}

\section{Results and discussions}

\subsection{Influence of lipase treatment on weight loss of polyester fabrics}

It is understood from Tables 4 and 5 that the increase in concentration of enzyme causes increase in weight loss in both the cases. The weight loss is significantly lower for lipasetreated samples than alkaline-treated, in similar concentrations ( $t$ value $=2.963 ; p$ value $=0.098)$.

There is a high degree of positive correlation between enzyme concentration and weight loss in both the cases, but the lipase treatment shows lesser $(0.955<0.981)$. The multiple $R$ of 0.981 indicated in Table 6 shows linear relationship, and $F$ ratio of 25.075 indicate that samples treated at different concentrations have significant weight loss.

\subsection{Effect on absorbency}

Table 7 values indicate that lipase-treated samples are having higher absorbency characteristics compared with the untreated and alkaline-treated fabrics.

\subsection{Effect of lipase treatment on surface characteristics of polyester fabrics}

The enzyme-treated polyester and blended samples are analyzed through SEM to know the effect of enzyme treatment

\begin{tabular}{|c|c|c|c|c|}
\hline Label & Fabric type & $5 \%$ & $10 \%$ & $15 \%$ \\
\hline PA & Alkaline-treated weight loss (\%) & $7.14 \%$ & $12 \%$ & $22 \%$ \\
\hline PL & Lipase-treated weight loss (\%) & $2 \%$ & $2.6 \%$ & $4.6 \%$ \\
\hline
\end{tabular}

Table 5. Statistical analysis

\begin{tabular}{|c|c|c|c|c|c|c|c|c|}
\hline Fabric & $\begin{array}{c}\text { Mean of } \\
\text { PA }\end{array}$ & $\begin{array}{c}\text { Mean } \\
\text { of PL }\end{array}$ & $\begin{array}{c}\text { Mean } \\
\text { difference }\end{array}$ & $\begin{array}{c}\text { 95\% confidence } \\
\text { interval (CI) }\end{array}$ & $\begin{array}{c}\text { Standard deviation } \\
\text { (SD) of difference }\end{array}$ & t value & $\begin{array}{c}\text { Degrees of } \\
\text { freedom (df) }\end{array}$ & p-value \\
\hline Polyester & 13.713 & 3.067 & 10.647 & -4.815 to 26.109 & 6.224 & 2.963 & 19 & 0.098 \\
\hline
\end{tabular}


on the surface etching. The SEM photographs of the alkaline- and lipase-treated samples are magnified (5000x) to understand the effect of treatments, respectively. The extent of damage is shown in Figure 2.

\subsection{Effect of lipase treatment on moisture regain}

FTIR tests reveal the additional functional groups due to alkaline and enzymatic hydrolysis. The addition of hydroxyl groups in polyester is responsible for the hydrophilicity. The following comparative FTIR spectrum reveals the modification in the functional chains, which are responsible for the property changes.

Figures 3-6 and Table 8 indicates that additional groups, such as aromatic rings, alkynes, esters, hydrogen bonds, and carboxylic acids, are present in treated fabrics. The stretching in the region of $3600-3200$ is responsible for the hydrophilicity of lipase- and alkaline-hydrolyzed polyester. The high peaks from $1700 \mathrm{~cm}^{-1}$ to $600 \mathrm{~cm}^{-1}$ indicate the original signals, such as characteristic spectra of stretching vibration band of $\mathrm{C}=\mathrm{O}$ at $1760 \mathrm{~cm}^{-1}$ and $\mathrm{C}-\mathrm{O}-\mathrm{C}$ stretching vibration band at 1097

Table 4. Effect of lipase treatment on weight loss of polyester fabrics

\begin{tabular}{|c|c|c|c|c|}
\hline Label & Fabric type & $\mathbf{5 \%}$ & $\mathbf{1 0 \%}$ & $\mathbf{1 5 \%}$ \\
\hline PA & Alkaline-treated weight loss (\%) & $7.14 \%$ & $12 \%$ & $22 \%$ \\
\hline PL & Lipase-treated weight loss (\%) & $2 \%$ & $2.6 \%$ & $4.6 \%$ \\
\hline
\end{tabular}

Table 5. Statistical analysis

\begin{tabular}{|c|c|c|c|c|c|c|c|c|}
\hline Fabric & $\begin{array}{c}\text { Mean of } \\
\text { PA }\end{array}$ & $\begin{array}{l}\text { Mean } \\
\text { of PL }\end{array}$ & $\begin{array}{c}\text { Mean } \\
\text { difference }\end{array}$ & $\begin{array}{c}95 \% \text { confidence } \\
\text { interval }(\mathrm{Cl})\end{array}$ & $\begin{array}{l}\text { Standard deviation } \\
\text { (SD) of difference }\end{array}$ & $t$ value & $\begin{array}{l}\text { Degrees of } \\
\text { freedom (df) }\end{array}$ & $p$-value \\
\hline Polyester & 13.713 & 3.067 & 10.647 & -4.815 to 26.109 & 6.224 & 2.963 & 19 & 0.098 \\
\hline
\end{tabular}

Table 6. Correlation and regression analysis

\begin{tabular}{|c|c|c|c|c|c|c|c|}
\hline Fabric & $\begin{array}{c}\text { Pearson correlation } \\
\text { coefficient }\end{array}$ & Multiple R & $\begin{array}{c}\text { Squared } \\
\text { multiple R }\end{array}$ & $\begin{array}{c}\text { Adjusted squared } \\
\text { multiple R }\end{array}$ & t value & $\mathbf{p}$ value & F ratio \\
\hline Polyester & $\begin{array}{c}\text { PE-0.955 } \\
\text { PA-0.981 }\end{array}$ & 0.981 & 0.962 & 0.923 & 5.007 & 0.125 & 25.075 \\
\hline
\end{tabular}

Table 7. Influence of lipase treatment on absorbency of polyester

\begin{tabular}{|c|c|c|c|}
\hline \multirow{2}{*}{ Label } & Fabric type & Wicking height (Cm) & Drop test (seconds) \\
\hline PU & Untreated fabric & 2.5 & 3.8 \\
\hline PA & Alkaline-treated fabric & 5.9 & 2.8 \\
\hline PL & Enzyme-treated fabric & 6 & 3.4 \\
\hline PAD & Dyed alkaline treated & 6.0 & 3.0 \\
\hline PLD & Dyed lipase-treated fabric & 7 & \\
\hline
\end{tabular}

A

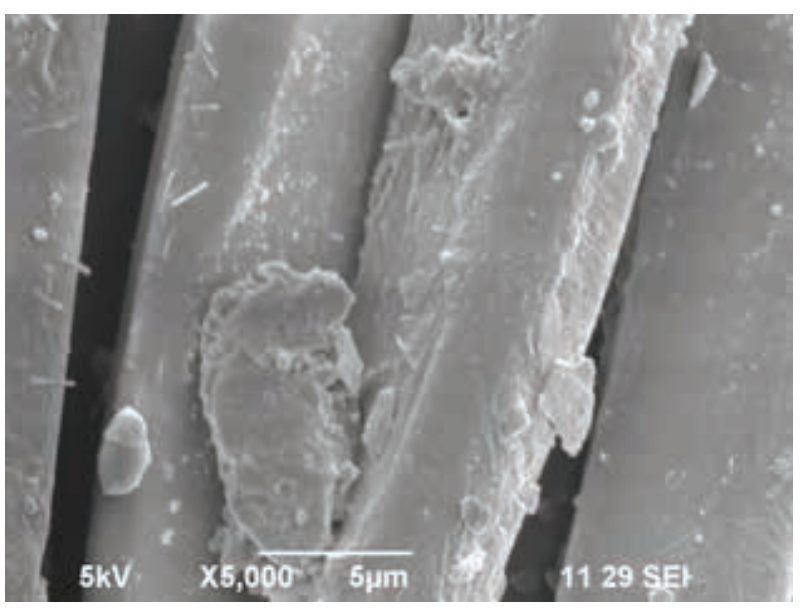

B

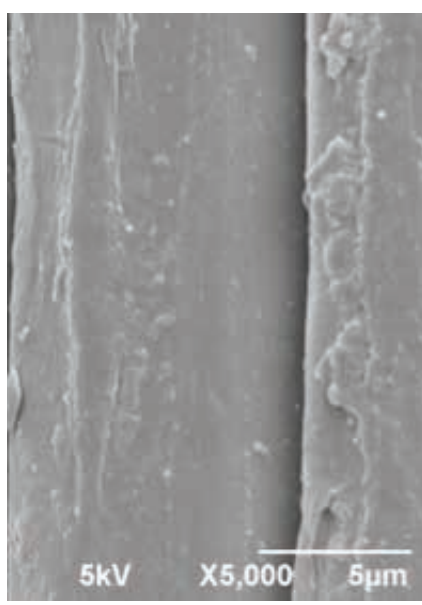

Figure 2. Scanning electron microscope (SEM) images of A (alkaline-treated) and B (lipase-treated) polyester fabric 


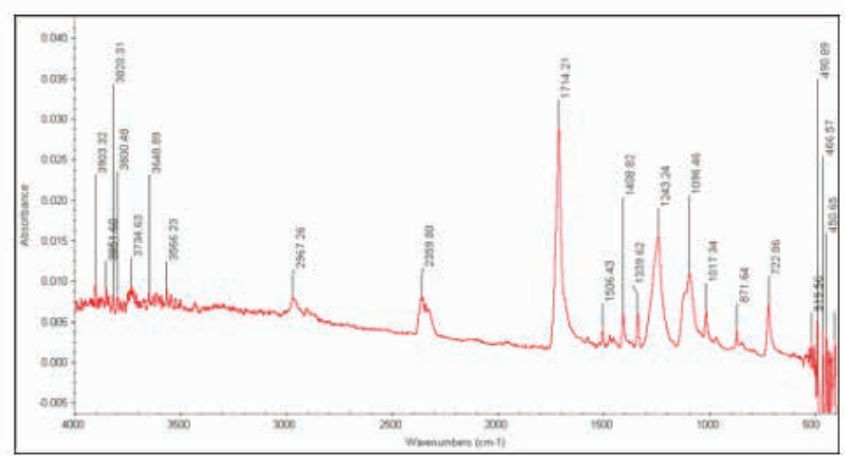

Figure 3. FTIR spectra of untreated polyester

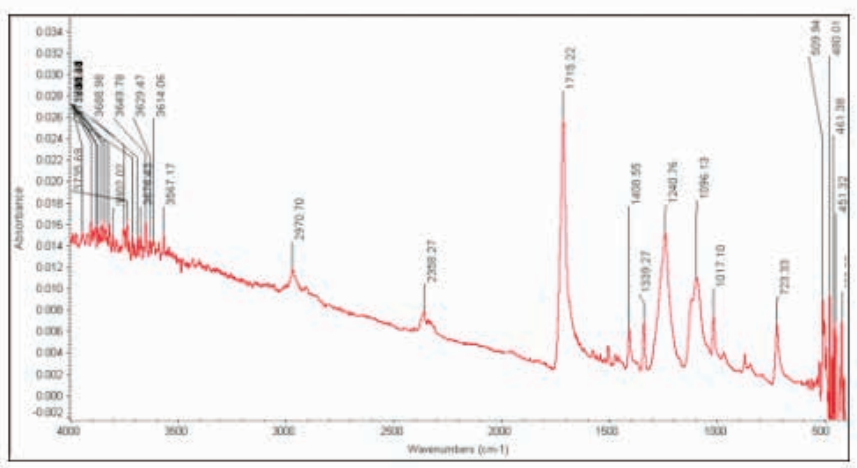

Figure 4. FTIR spectra of alkaline-hydrolyzed polyester

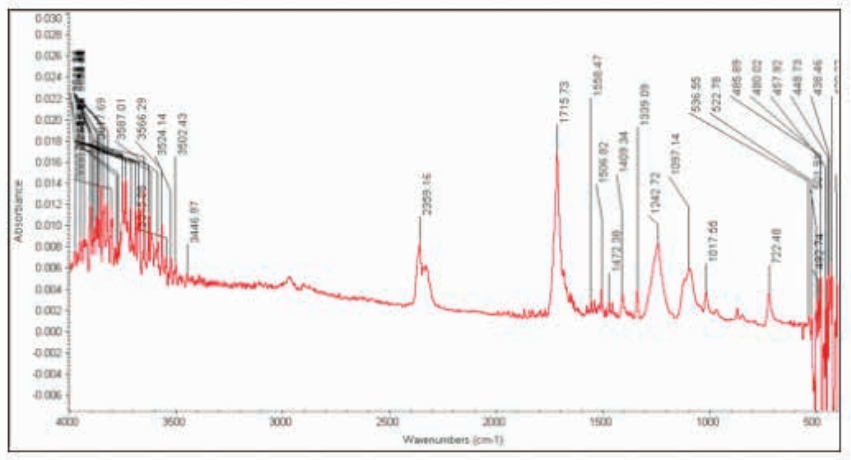

Figure 5. FTIR spectra of lipase-hydrolyzed polyester

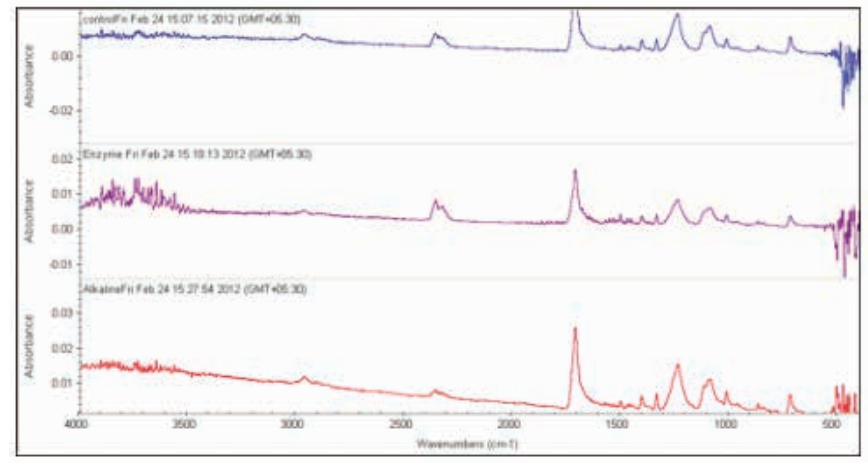

Figure 6. FTIR comparison spectra of untreated and hydrolyzed polyester

Table 8. Interpretation of Fourier Transform Infrared (FTIR) spectra of polyester

\begin{tabular}{|c|c|c|c|c|}
\hline Group & Vibration & Type & Range & Inference \\
\hline Aromatic rings & Ring stretch & Symmetric & 1600,1500 stretch & C=C \\
\hline Alkynes & Bend & Band & $700-610(\mathrm{~b})$ bend & $\mathrm{C}-\mathrm{H}$ \\
\hline Hydrogen-bonded & Stretch & OH stretch & $3600-3200(\mathrm{~b})$ stretch & $\mathrm{O}-\mathrm{H}$ \\
\hline Esters & Stretch & C=O & 1760-1670(s) stretch & $\mathrm{C}=\mathrm{O}$ \\
\hline Carboxylic acids & Stretch & Antisymmetric & $3000-2500(\mathrm{~b})$ stretch & $\mathrm{COOH}$ \\
\hline
\end{tabular}

Table 9. Water vapor permeability of lipase-treated polyester fabric

\begin{tabular}{|c|c|c|}
\hline Treatment type & Label & Water vapor permeability $(\mathrm{g} / \mathrm{m} 2 /$ day $)$ \\
\hline Untreated polyester fabric (100\%) & PU & 1260 \\
\hline Alkaline-treated polyester fabric & PA & 1660 \\
\hline Lipase-treated polyester fabric & PL & 1980 \\
\hline Dyed alkaline treated & PAD & 2761 \\
\hline Dyed lipase-treated fabric & PLD & 1820 \\
\hline
\end{tabular}

and $1240 \mathrm{~cm}^{-1}$. All these peaks confirm the existence of ester linkage. This is attributed to the carboxylic group $(-\mathrm{COOH})$ introduced on the surface due to hydrolysis of the ester linkage. The stretching is very high in the case of lipase-hydrolyzed polyester, which makes the enzyme treated more hydrophilic. It is also noted that the presence of basic functional groups inherent in the polyester materials.

\subsection{Effect of lipase treatment on water vapor permeability of polvester fabrics}

From Table 9, it is understood that the alkaline- and lipasetreated polyester fabrics are having improved water vapor permeability compared with the untreated polyester fabrics. It is mainly due to the degradation of chain links and the addition of hydroxyl groups. 
Table 10. Polyester fabric K/S values

\begin{tabular}{|c|c|c|c|c|c|c|c|c|}
\hline \multirow{2}{*}{ Type of treatment } & \multirow{2}{*}{ Label } & \multicolumn{7}{|c|}{ Wave length (nm)/K/S value } \\
\cline { 3 - 9 } & & 400 & 450 & 500 & 550 & 600 & 650 & 700 \\
\hline Alkaline treated, dyed & PAD & 3.904 & 5.897 & 4.167 & 1.503 & 0.169 & 0.023 & 0.014 \\
\hline Lipase treated, dyed & PLD & 4.021 & 5.79 & 3.685 & 1.318 & 0.146 & 0.018 & 0.012 \\
\hline
\end{tabular}

Table 11. Effect of lipase treatments on compression and shear properties of polyester

\begin{tabular}{|c|c|c|c|c|c|c|c|c|}
\hline Fabric type & Treatment type & Label & LC & $\begin{array}{c}\text { WC } \\
\text { (gf } \mathrm{cm} / \mathrm{cm}^{2} \text { ) }\end{array}$ & RC (\%) & $\begin{array}{c}G \\
\text { (gf/cm.deg) }\end{array}$ & $2 H G(\mathrm{~g} / \mathrm{cm})$ & $\begin{array}{l}2 \mathrm{HG5} \\
(\mathrm{g} / \mathrm{cm})\end{array}$ \\
\hline \multirow[t]{5}{*}{$\begin{array}{c}100 \% \\
\text { polyester }\end{array}$} & Untreated & PU & 0.273 & 0.062 & 43.55 & 0.52 & 0.50 & 1.79 \\
\hline & Alkaline treated & PA & 0.303 & 0.069 & 42.03 & 0.56 & 0.79 & 2.24 \\
\hline & Lipasetreated & PL & 0.292 & 0.062 & 51.61 & 0.61 & 0.90 & 2.17 \\
\hline & Dyed alkaline treated & PAD & 0.304 & 0.070 & 42.06 & 0.57 & 0.78 & 2.20 \\
\hline & Dyed lipase treated & PLD & 0.308 & 0.064 & 54.69 & 0.59 & 0.66 & 2.13 \\
\hline
\end{tabular}

LC, linearity of compression thickness; RC, compression resilience; WC, compression energy.

\subsection{Effect of enzyme treatment on dye uptake of polyester fabrics}

The alkaline-treated, lipase-treated, and dyed fabrics are tested by reflectance type spectrophotometer to know the $K / S$ values. These values help understand the difference in luster and color values. The treatment offers better dye uptake that enhances the color values.

From Table 10, it is understood that lipase-treated fabrics shows higher reflectance and lower K/S values. Similar trend is observed in dyed fabrics. This clearly shows that treatment enhances the dye uptake of the polyester fabrics.

\subsection{Effect of enzyme treatment on the low-stress mechanical properties of polyester}

The Kawabata evaluation tests are used for evaluating compression and shear properties in lipase-treated and untreated polyester fabrics, as it reveals the effectiveness of the enzyme treatment.

Table 11 shows that lipase treatment reduces the linearity of compression and compression energy, whereas enhances the compression resilience in polyester fabrics. The enzyme treatment makes the fabric much softer, and it retains its original shape as quickly as possible while applying low stress load. Hence it is possible to infer that lipase treatment makes the polyester fabric with low shear rigidity, which indicates that the fabric will conform to 3-dimensional structures while applying low stress.

\section{Conclusions}

Alkali treatment offers more surface itching and weight loss, whereas lipase enzyme attacks the polymer chain, which causes mild itching and low weight loss. The treated fabrics have improved water vapor permeability compared with the untreated polyester fabrics. It is mainly due to the degradation of chain links, which ultimately enhances the dye uptake and improves the moisture uptake. Enhanced compression resilience in polyester fabrics makes them much softer and helps to retain its original shape as quickly as possible while applying low stress load, which makes the polyester fabric with low shear rigidity. The statistical result shows that the treatment is significant and effective in modifying the fabric properties.

\section{References}

[1] Lee, S. H., Song, W. S. (2010). Surface modification of polyester fabrics by enzyme treatment. Fibres and Polymers, II(1), 54-59.

[2] Lee, S. H., Song W. S. (2008). Optimisation of enzymatic treatment of polyester fabrics from porcine pancreas. Fibres and Polymers, 9(4), 423-430.

[3] Kim, H. R., Song, W. S. (2006). Lipase treatment of polyester fabrics. Fibres and Polymers, 7(4), 339-343.

[4] Gandhi, N. N. (1997). Applications of lipase. JAOCS, 74(6), 621-634.

[5] Hsieh, Y. L., Cram, L. A. (1998). Enzymatic hydrolysis to improve wetting and absorbency of polyester fabrics. Textile Research Journal, 68(5), 311-319.

[6] Latta, B. M. (1984). Improved tactile and sorption properties of polyester fabrics through caustic treatment. Textile Research Journal, 54(11), 766-775. 
[7] Rahman, M., East, G. C. (2009). Titanium dioxide particleinduced alkaline degradation of PET: Application to medical textiles. Textile Research Journal, 79(8), 728-736.

[8] Wavhal, S. D., Balasubramanya, R. H. (2011). Role of biotechnology in the treatment of polyester fabrics. Indian Journal of Microbial, 51(2), 117-123.

[9] Karaca, B., Demir, A., Ozdogan, E., Ismal, O. E. (2010). Environmentally benign alternatives: Plasma and enzymes to improve moisture management properties of knitted PET fabrics. Fibres and Polymers, 11(7), 1003-1009.

[10] Haghighatkish, M., Yousefi, M. (1992). Alkaline hydrolysis of polyester fibres-structural effects. Iranian Journal of Polymer Science and Technology, 1(2), 56-61.

[11] Schimper, C. B., Ibanescu, C., Keckeis, R., Bechtold, T. (2008). Advantages of a two-step enzymatic process for cotton-polyester blends. Biotechnology Letters, 30, 455459.

[12] Nimchua, T., Eveleigh, D. E., Sangwatanaroj, U., Punnapayak, H. (2008). Screening of tropical fungi producing polyethylene terephthalate-hydrolyzing enzyme for fabric modification. Journal of Industrial Microbiology and Biotechnology, 35, 843-850.

[13] Haji, A., Reza, M. A., Malek, F. M. (2011). Comparative study of exhaustion and pad-steam methods for improvement of handle, dye uptake and water absorption of polyester/cotton fabric. Chemical Industry and Chemical Engineering Quarterly, 17(3), 359-365.
[14] O'Neill, A., Cavaco Paulo, A. (2004). Monitoring biotransformation in polyesters. Biocatalysis and Biotransformation, 22(5/6), 353-356.

[15] Eberl, A., Heumann, S., Kotek, R., Kaufmann, F., Mitsche, $S$., et al. (2008). Enzymatic hydrolysis of PTT polymers and oligomers. Journal of Biotechnology, 135, 45-51.

[16] El-Shemy, N. S., El-Hawary, N. S., El-Sayed, H. (2016). Basic and reactive-dyeable polyester fabrics using lipase enzymes. Journal of Chemical Engineering and Process Technology, 7, 271.

[17] El-Ola, S. M. A., Moharam, M. E., El-Bendary, M. A. (2013). Optimum conditions for surface modification of PET by lipase enzymes produced by Egyptian bacilli in comparison with standard one. Indian Journal of Fibre \& Textile Research, 38, 165-172.

[18] Shahidi, S., Wiener, J., Ghoranneviss, M. (2013). Surface modification methods for improving the dyeability of textile fabrics. Web site: doi:10.5772/53911.

[19] Abdel-Halim, E. S., Abdel-Mohdy, F. A., Al-Deyab, S. S., ElNewehy, M. H. (2010). Chitosan and monochlorotriazinyl$\beta$-cyclodextrin finishes improve antistatic properties of cotton/polyester blend and polyester fabrics. Journal of Carbohydrate Polymers, 82(1), 202-208. 